\title{
Environmental Factors Affecting Human Resources Management Activities of Turkish Large Firms
}

\author{
Kurtuluş Yılmaz Genç ${ }^{1}$ \\ ${ }^{1}$ Giresun University, Faculty of Economics and Administrative Sciences, Giresun, Turkey \\ Correspondence: Kurtuluş Yılmaz Genç, Giresun University, Faculty of Economics and Administrative Sciences, \\ Giresun, Turkey. Tel: 90-534-212-2951. E-mail: kyilmazgenc@gmail.com
}

Received: August 9, 2014

Accepted: September 17, $2014 \quad$ Online Published: October 22, 2014

doi:10.5539/ijbm.v9n11p102

URL: http://dx.doi.org/10.5539/ijbm.v9n11p102

\begin{abstract}
The basic aim of this study is to present and examine environmental factors affecting human resource activities, which based upon a research conducted on Turkish large firms. Factors that affect human resource management (HRM) activities were divided into two, as internal and external elements. The data for the research were gathered with a survey, and analyzed with various statistical methods. Accordingly, it was achieved that, companies take these internal and external elements into consideration in a high or at least moderate level in general. Moreover, it was found that, "priorities of top management", "legislations/regulations", "changes in national economy", and "qualities of employees" are the top factors affecting HRM activities. It was also seen that, there is no statistically significant relation between industries, the year of foundation, city of headquarters, ownership type, size and the means of internal or external environmental factors affecting HRM activities. The results demonstrate the fit for internal factors and fit for external factors. Also, it was found that, internal and external environmental factors are significantly associated. Thus, HRM activities are closely integrated with environmental elements, which, should always be considered.
\end{abstract}

Keywords: Turkish large firms, human resources management activities, environmental factors

\section{Introduction}

As the business environment became an important base for any type of organization, also human resource function has its own internal and external environment, which make related issues very complex. There are many studies about the relation between environmental factors and business activities since 1950's. Equally, there are also many researches and articles on human resource management (HRM) and environmental factors link. In these studies (e.g., Kane \& Palmer, 1995; Buller, 1988; Cascio, 1993; Jackson, Schuler, \& Rivero, 1989; Jain \& Murray, 1984; Tiwari \& Saxena, 2012), the following environmental elements were generally linked with HRM activities, in terms of the source of pressure or any type of influence from inside and outside. The internal environment of HRM function might include organizational mission/purpose, organizational strategy/objectives, actions of corporate headquarters, size of an organization, structure of an organization, history/traditions/past practice, priorities of top management, priorities of line managers, issues of power and politics, impact of HRM theory, research and writings, impact of education and training in HRM, impact of overall HRM strategy, and cultural and political characteristics of employees. Equally, the external environment of HRM function might include changes in international economy, changes in technology, changes in national economy, national culture and traditions, industry/sector characteristics, legislation/regulation, actions of unions, actions of competitors, impact of professional organizations, HRM staff's experiences in other organizations, and general education policies and implementations.

This study investigates the factors affecting HRM activities of Turkish large firms, in Today's turbulent business environment. Also, the degree and prevalence of strategy determination for HRM, is evaluated. Accordingly, in the first part of the paper, related literature is discussed. Then, in the second part, the results of the field research are given and discussed; and finally, a general conclusion is presented.

\section{Literature Review}

The literature on human resource management and organizational environment relationship is becoming widened continuously. There are many studies about the "strategic" dimension of human resource (Barney, 1995; Barney 
\& Wright, 1997; Miles \& Snow, 1984; Schuler \& Jackson, 1989; Truss \& Gratton, 1994; Wright \& McMahan, 1992), which mainly discussed the importance of it, in terms of completing organizational strategies. In connection with this, there are many writers who focused on the environmental factors affecting human resource management practices (Kane \& Palmer, 1995; Buller, 1988; Cascio, 1993; Jackson, Schuler, Rivero, 1989; Jain \& Murray, 1984; Powell, 1990; Schuler, 1990; Sparrow, 1994; Terpstra \& Rozell, 1993; Tsui \& Milkovich, 1987; Wright, McMahan, \& McWilliams, 1994).

Kane and Palmer (1995) discussed the importance of environmental factors, especially the role of strategy in human resource (HR) practices of firms in Australia. Accordingly, they founded that, the overall human resource management (HRM) strategy, has only a relatively minor impact on HRM practices, when compared with other factors.

HRM function has several roles in an organization; which is being a strategic partner that integrates business and HR strategies; develops and strengthens business processes and provides essential HR services; satisfies personnel for their demands; increase organizational effectiveness and efficiency by creating change processes (Ulrich, 1998, cited by Rosman \& colleagues, 2013).

\subsection{External Environmental Factors}

\subsubsection{Changes in the International Economy}

Today, the changes in the international economy affect all of the national economies in a short time. This is because of the integration of world economies. Accordingly, any recession in a country which is important in world economy, might easily stimulate same conditions in other economies. Therefore, in the unstable terms of world economy, the bargain between unions and firms can be harder. In other words, negative developments for economies would result in undesired situations. That is to say, employment rates and sales would degrease, unemployment would rise up, and so the social status of workers weakens.

On the other hand, the stabilization or growth of world economy as a whole would affect any national economy in the positive way. So, the unemployment rates will degrease, the general wage and salary levels will increase, and as a result employees will be stronger. Thus, unions can gain more in bargaining for the rights of employees. Besides, in this type of terms, top managements of firms would also behave in the favor of their personnel because of the increased revenues. Therefore, human resource (HR) policies of companies would change in the affirmative way. In particular, positive developments in international economy would increase exportation rates. This will enlarge manufacturing, which needs an increased employment proportion.

In Turkey, the economic crises in 2001 resulted in degrease of demand, and so manufacturing and employment. Besides, many firms cut the wages and salaries of their employees. At the same time, some firms practiced obligatory vacation for large numbers of their personnel which lasted almost a year. Again, in 2008, like many other countries, Turkey was under the influence of economic crises in which, similar results were observed. Similarly, Kane and Palmer (1995) cite economic recession resulted in reducing workforce in Australia. In the same way, Mello (2006) discusses economic trends, such as unemployment rate, would have influences on any achievement of an organization.

\subsubsection{Changes in Technology}

Changes in technology could provide more appropriate infrastructure for mental and physical human health. To put it another way, any development in science and so, technology would make it possible to set up a better organizational substructure. Moreover, with this type of progress, also the incomes of business organizations will grow, which can be expected to improve the wages and salaries of employees. The increase in the number of technological alternatives or innovation in business functions might create a positive image for firms which can increase revenues. Furthermore, changes in technology can make it possible to have improved human resource functions such as selection, recruitment, educating, training, performance appraisal or observing, determining wages and salaries. In addition, international developments in human resource management (HRM) can be learned faster; and, be implemented. Besides, all of the human resource functions can be practiced in a more effective way.

Changes in technology can also have negative impacts on human resource policies. This type of circumstance can degrease the need for labor, which can result in a lower employment level. As a result, the demand for qualified workers would be higher, so educating and training costs will increase. Also, policies, such as encouragement for retirement could take place more dominantly, which increases the spending of social security. At the same time, technological developments can make some employees functionless, who are very valuable in conventional or old style manufacturing. Therefore, some workers can become low-spirited, and can be put out 
of organization by retirement, breaking contract, or other ways. This can be called as social costs of technological developments. On the other hand, the need for qualified workers for using technology can increase personnel spending.

As pointed out by Bingöl (2006), technological developments require flat organizational structures to allow highly qualified personnel demonstrate their creativeness. Accordingly, firm managements employ staffs who are knowledgeable about information technologies; as a sign of changing HRM policy and strategy. Similarly, Kane and Palmer (1995) pointed out that, especially the prevalent usage of microprocessor based technology, affects recruitment, staffing, the knowledge, skills and abilities of workforce. In addition, Jackson and colleagues (1989), stated that producers, which use flexible specialization require less skills than manufacturers that use mass production. Tiwari and Saxena (2012) pointed out that, technology provides new methods for HRM practices. DeFillippi (2002) suggests that, technology alters the roles of human resource.

\subsubsection{Changes in the National Economy}

Changes in the national economy directly or indirectly affects human resource activities of firms, in terms of recruitment, employment, redundancy implications, compensation and rewards/salaries. As mentioned above, any recession in national economies might result in the reduction of workforce, or at least significant cuts in wages or salaries and social support spending.

Rosman and colleagues (2013) stressed the significant interference of national economy on HR policies. In the same way, Mello (2006) points out that, organizations should predict the future of economy and plan their functions. Accordingly, economic conditions might have an important affect on labor force, by changing the type and number of personnel demanded. In other words, when an economy stabilizes, competition for qualified human resources increases.

The positive developments in national economies would increase labor demand, so the wages and salaries. The stabilization of internal economies strengthens belonging, togetherness, and cooperation because of satisfying outcomes which benefits both shareholders and personnel. Any downgrade in the stocks and market values would easily damage the relations between owners and employees.

The position of national economies, in terms of stability and wealthiness might attract qualified people from other countries, which gives better recruitment opportunities to firms (Kabene, Orchard, Howard, Soriano, \& Leduc, 2006).

As it was discussed above, Turkey experienced so hard conditions in 1994 and 2001, because of economic crises in national economy. Therefore, first recession, and then downsizing made Turkish firms end work contracts, or shut their doors, in other words stop operating, which caused hundreds of thousands of people unemployed, or low waged. Besides, labor unions reevaluated their policies because of those special conditions.

\subsubsection{National Culture and Traditions}

Natural culture and traditions may affect human resource management activities in terms of transferring related national characteristics to the business life. Behavioral types or attitudes of top managers and human resource managers are under the influence of local culture therefore it has direct or indirect impacts on human resources activities. In countries that are more closed to the entire world, firms could have HR activities which are more affected from national characteristics, but this is related to the size, institutionalization level and international operations of those firms. The countries that are fully integrated to the international business and economics should have firms which are more open to the impacts of universal culture. Large firms are expected to be more open to international impact, because, this is essential for them to operate in foreign markets.

National culture and traditions also affects HRM activities by changing ways of response of management for local sensitivities. Cultural values should be taken into consideration by firms so that, not to confront public reaction for their actions.

As Bingöl (2006) stated, firms should consider the values, myths, behavioral types, rituals, and expectations of society, when they are identifying HRM policy and strategies. Thus, organizations would be stronger in competition. Equally, if institutions put the ethics of people into account, it would be easier for them to behave in socially responsible way. In relation with this, Kane and Palmer (1995) cite the linkage between the differences of HRM practices and national cultures. Tsui and Milkovich (1987) examined the multiple constituency approach, which explains the practice of human resource department through client expectations. Tiwari and Saxena (2012) argued the link between national culture and HRM activities. Chandrakumara and Sparrow (2004) achieved the result that, national culture is one of the important elements which determine organizational perspectives in establishing structure for effective HRM practices. 
Turkish society is generally conservative, loyal to their traditional culture. Therefore, firms operating in Turkey should be more sensitive to local cultural characteristics. Besides, collaboration between family members is so general, which makes the results of unemployment or low wages and salaries lighter. Moreover, Turkish people see the state or any employer as "the father"; and this approach minimizes opposing movements, so strikes. Accordingly, labor unions have less power in that culture, which weakens bargaining power against firms. As a result, the HRM strategy and policies can be determined more independently by companies, especially wages and salaries. In relation to this, another reason can be the characteristics of labor market in Turkey, as low cost, much populated, and largely educated. In addition, Turkish labor has close links with rural life or villages. In other words, they are also land owners, which give people other income opportunities, and make them more tolerant.

\subsubsection{Industry/Sector Characteristics}

Sectorial characteristics might affect human resources management activities in different ways. Sectors such as manufacturing, retail, marketing or chemistry, construction, food or services as education, and health shall create its own type of human resources management system. In some sectors, such as services in terms of education and health, or banking are required to be more sensitive to the needs of its human resources. Also, these industries are more dependable to the characteristics, skills and abilities of their human resource.

Some sectors offer higher general income level, such as health. On the other hand, some industries which depend on continuous technological development and innovation give higher personal satisfaction. In addition, it is easier to appraise performance because of their personnel focused work schedule.

Sectors such as mining and construction require highest sensitivity to work area security. In other words, firms in these types of industries should behave in accordance with the necessities of security to avoid compensation or penalties. In fact, these types of attitudes are necessary to protect human life, health and dignity.

Consequently, companies should behave in a competitive way, which requires them consider the HRM strategy and policies of competitors, when they are identifying principles that schedule practice. For example, if a firm offers low wage or salaries, it would employ personnel who have lower levels of skills, abilities (Bingöl, 2006); so qualifications. Terpstra and Rozell (1993) pointed out the differences of HRM practices according to industrial characteristics, like the characteristics of training. However, Jackson and colleagues (1989) argued that, there is no difference between manufacturing and service firms, such as training hours. Tiwari and Saxena (2012) suggest that, HRM practices vary according to manufacturing processes.

\subsubsection{Legislation/Regulation}

All of the policies for human resource management should be in accordance with legal necessities. Firms should behave in the frame of regulations which are the implementation of law or putting it into practice. To put it more simply, also, law structures HRM practices. Accordingly, Tiwari and Saxena (2012) pointed out that, HRM implementations should be adapted to the regulations of countries. Therefore, the differences of HRM practices also depend on these legislation and regulations. Equally, Kane and Palmer (1995) discussed that equal opportunity, occupational health, and industrial relations can be influenced primarily by the legislation. Also, Mello (2006) argues that, legislation and regulation have impacts on every function and activity of an organization, so, on human resource management decisions. Similarly, Mabey and Salaman (1995) identify the importance of government policies and legislation on strategic training and development activities.

In Turkey, every HRM implementation should be in accordance with the "Labor Law". Also, the "Unions Law" frames the mentioned practices. Every business organization should consider related law and regulation for any of its functions. Unclear or "empty" areas, in terms of the absence of law should be fulfilled by lawful actions. Accordingly, the labor inspectors control companies for their related human resource practices and report any illegality that results in penalties. Legality of any function, say human resources function, makes the image of an organization stronger. Consequently, firms should take national and international legislation into account while "managing" their human resource.

According to the current Turkish Constitution, no one can be employed in jobs which are not suitable to their age, gender, or strength. Equally, children and women, and people who have disabilities should be supported. Besides, everyone has a right to have a rest. In addition the conditions of retirement, as an obligation for firm the employment of former convicts, and disabled people are all regulated by law. Therefore, related law protects Turkish people or who are employed in Turkey as workers or any types of personnel.

\subsubsection{Actions of Unions}

Actions of unions also structure the human resource management practices of firms. Business organizations 
should allow unions to be active in an organization in the frame of unions' law. Accordingly, they should consider the demands of unions when they are designing their future plans for their human resource functions. At the same time, many sub functions of HRM are determined and structured through labor contracts. In other words, educating, training, deciding wages and salaries, breaking contract and compensation are all in the content of agreement with unions.

Unions also affect other sectors by threading them (Bingöl, 2006; Mabey \& Salaman, 1995), in terms of the level of wages and salaries, physical conditions, and compensation. Therefore, the actions of companies in terms of human resource management are realized under the impacts of unions. In relation to this, it was found by Jackson and colloquies (1989) that, organizations with a union use more formal performance appraisals, and appraisal results to identify training needs. Moreover, the compensation or bonuses of personnel were tied to their performance, in organizations with a union (Jackson et al., 1989). Furthermore, Tsui and Milkovich (1987) affirm that, human resource related activities such as industrial relations, security and health are mostly realized responding the demands of unions. In addition, unions limit the flexibility of managements, in terms of adopting HR policies (Rosman, Shah, Hussain, \& Hussain, 2013). Finally, the findings of Rosenzweig and Nohria (1994) also support the link between unions and HRM practices.

In Turkey, there are many unions organized in different sectors. Although the labor movement has a history of more than hundred years; unions got the enlarged rights of free actions in 1962. In the years of military law, in 1971, and in 1980's union influence on HRM declined. When military law ended, Turkish labor movement gained momentum and had impacts on business life. Then, in 1992, state officials also gained the right to have a union; and also, became more organized to improve their conditions. Consequently, Turkish unions have significant impacts on Turkish business life and human resource implementations.

\subsubsection{Actions of Competitors}

Although it is better to be proactive and so leader in a sector, to react to the actions of competitors is also a widely seen situation in business life. Rival firms can increase the wages and salaries, or improve work conditions, offer better social support programs and so on; which also is reacted effectively. If competitors offer better rights and conditions to their employees, any firm should respond, in terms of satisfying the expectations its employees, in order to keep them as a member of organization.

Today, human resource is seen as the basic internal resource that can be the source of competitive advantage. Accordingly, valuable, unique, well organized and inimitable human resource can be the source for competitive advantage (Barney, 1991; Barney, 1995; Barney \& Wright, 1997). So, as a proactive behavior companies should develop this type of employees in order to get advantage on their rivals and sustain it. Accordingly, to have this type of personnel, firms should have advanced and efficient selection, recruitment, training and education, performance appraisal, and wages and salaries sub HR functions. As a result, enterprises can lead their sectors by the help of their human resources.

Wright and colleagues (1994) cited "The Firm Specific Human Capital Theory" of Steffy and Maurer (1988). According to this theory, the variance for individual contribution to firm changes when the demand and supply for labor is not equal. In other words, demand and labor for firms are both heterogeneous. So, organizations need different types of employees, who have changing skills and abilities, for various jobs. Consequently, this situation can be another source or explanation for the different types of HRM practice.

The study of Rosenzweig and Nohria (1994) affirms the impact of competitors on HRM policies and implications, for benefits, gender composition, training, executive bonus, and participation. In addition, Tiwari and Saxena (2012) assert that, comprehensive HRM activities might provide competitive advantage.

\subsubsection{Impact of Professional Organizations}

The impact of professional organizations as consultants have also impacts on HRM. Today, there are many consultancy firms in every country that support business life. So, these institutions affect the HRM activities, so the whole organizations as well.

There are many consultancy firms which are in service for organizations from SME's to large firms operating in Turkey. Therefore, these firms contribute increasing the quality of business functions, so the HRM. Thus, the level of satisfaction of customers also increases with products and services that respond their expectations.

\subsubsection{HRM Staff's Experiences in Other Organizations}

The experiences of HRM staff of other organizations might also affect the HR implementations of a firm. In other words, any establishment in an industry has opportunity to benefit from the accumulation of knowledge in 
that sector. Accordingly, cases about any HR function in other organizations should be evaluated to take lessons, in order to prevent mistakes in current policies and practices.

It is clear that, every organization has special characteristics, which separate them from others. Equally, environmental conditions or factors that affect organizational structure and practices are contingent. However, this does not decrease the significance of integrating other institutions' experiences to organizational strategy, and practice.

In Turkey, competitiveness becomes harder day by day in business as in the entire world, which also presents countless examples for companies, related with any function.

Human resource management might set performance standards (Tsui \& Milkovich, 1987). These standards should depend on the achievements through organizational purposes, in the frame business strategy. At the same time, these standards can also be determined in some parts, through the practices and results of competitors.

\subsubsection{General Education Policies and Implementations in Turkey}

General education policies and implementations determine the qualities of people, so the labor force. Accordingly, universities and other schools of a country develop human resources, so affect the efficiency, productivity, and so profitability of firms. Furthermore, every new personnel carry his or her experiences, so education and training to organizations.

If a candidate employee is ready to work, then the education, training and development costs of employer firm will minimize. Moreover, it would also affect HR outcomes such as performance, and turnover.

\subsection{Internal Environmental Factors}

\subsubsection{Organizational Mission/Purpose}

All of the organizations should behave through their mission statements. Mission statements demonstrate the framework that firms should operate in. Therefore, it also determines the human resources policies, indirectly. As a mission statement shows the basic reason behind the foundation of an organization, it gives a base, in terms of orientation, to any function of it. Accordingly, human resources policies and practices should be consistent with this statement. On the other hand, these types of statements integrate functions through purposes.

As Bart and Baetz, (1998), and Bartkus and colleagues $(2004 ; 2006)$ pointed out, by presenting values and philosophy, mission statements facilitate both management's and employees' non routine decision making. In addition, an ideal mission statement can be the source of policies to motivate or inspire employees, with a content including words about excellence and societal benefit.

\subsubsection{Organizational Strategy/Objectives}

Organizational strategy reflects the set of methods to achieve purposes and requires the restructure of principles, rules, departments, simply mindset in an institution. The human resource policies of a firm should support activities to implement organizational strategy. Therefore, the selection, recruitment, education and development, performance appraisal and reward sub functions of HRM should be appropriate to the general strategy of establishment. The successful practices of human resource management sub functions facilitate to achieve objectives. In other words, sufficient organizational outcomes can be gained easier through the adaptation of human resource policies to business strategy.

Every unit or function of an organization should adapt its strategy to organizational strategy. This is the necessity of strategy implementation for achieving goals (Mintzberg, Lampel, Quinn, \& Ghoshal, 2003; Wheelen, \& Hunger, 2002; Wright, Kroll, \& Parnell, 1998). Therefore, human resource strategy or implementation should fit organizational strategy.

Establishments should consider targets, purposes, policies and strategies when they are designing and practicing their HRM functions (Mabey \& Salaman, 1995; Mello, 2006). To put it more simply, plans for human resource should match plans for organization in general. Buller (1988) affirmed that, organizational strategy is affected by and affects HR strategy, which shows a two-way linkage. It is clear that, business planners should consider HR; or HR staff should involve to that process. In connection with this, Jackson and colleagues (1989) achieved the results that, firms implementing an innovation strategy use wage, salary and rewards to support this, in order to employ personnel who have high levels of expertise. Moreover, it was also found that compensation policies change according to the type of employees.

According to the "strategic human resource management" approach, human resources activities should fit both internally and externally. Internal fit, is about the integration of HR activities, like selection, recruitment, 
performance appraisal, or wages and salaries. External fit is about the adaptation HR strategy to business strategy. In the same way, the contingency approach of strategic human resource management suggests that HR strategy should be harmonious with organizational strategy (Delery \& Doty, 1996; Miles \& Snow, 1984; Wright \& McMahan, 1992).

\subsubsection{Actions of Corporate Headquarters (If Applicable)}

Corporate headquarters determine purposes and organizational strategy. Their philosophy and vision structure the framework for the policies of human resource management. Equally, corporate headquarters are responsible to form unified strategies across its branches. Therefore, human resource policies should also be a part of those common strategies.

Corporate headquarters could also have priorities in terms of the policy of selection, recruitment, education and development, retain, wage and salaries, performance appraisal and social support. Accordingly, skills and abilities, education, experience, loyalty, political view, gender, ethnicity, or anti-discrimination can be the criteria or the source of HRM practice.

\subsubsection{Size of the Organization}

The size of an organization, which is very important for the extent of HRM activities, can be measured especially through the number of employees, amount of income for a year, or the sum of production. Accordingly, HR practices, in terms of number of functions, will be higher in a large firm than a small or medium sized enterprise (SMEs). Large firms, such as international or multinational firms should add many new dimensions to their HR implementations. Also, new developments or innovations in practices generally and continuously occur in large organizations, through their qualified, knowledgeable personnel, widened business horizon and sophisticated culture. To put it another way, SMEs, as a result or reflection of their size, generally have personnel management functions, which could include either simple or complicated activities.

The size of an organization is also significant for managerial style, in terms of autocratic or participative. Large organizations can be more democratic, so, their departments or branches might be more autonomous. In these types of establishments, decentralization is a necessity for an effective management. So, there is less control and more self confidence. Conversely, small and medium sized enterprises generally have centralized organizational structure and so, managerial practice. Therefore, human resource of those firms is under close control of their managers.

There are studies in the literature which state the significant relationship between organizational size and HRM activities (i.e. Jackson et al., 1989; Terpstra \& Rozell, 1993). Accordingly, Jackson and colleagues (1989) found expectedly that, the percentage of employees who face formal appraisal systems in small firms is higher, when compared with larger ones. Similarly, same authors also achieved that, employees in larger organizations received less hours of training. However, Rosenzweig and Nohria (1994) found no relation between HRM practices and the size of organizations.

\subsubsection{Structure of the Organization}

The structure of an organization, basically, can be vertical or horizontal. Vertically structured organizations, has hard hierarchy, which reflects centralization. In this type of organizations, human resource is under tight control of upper hierarchical levels. On the other hand, horizontal organizational systems provide more flexibility to employees.

There are some studies (e.g. Buller, 1988; Jackson et al., 1989), which showed the link between organizational structure and types of behaviors. Accordingly, the writers achieved that, product-based firms use wages, salaries and rewards to focus managers and other personnel on long-term purposes.

\subsubsection{History/Traditions/Past Practice}

The history of organizations would reveal what is good, and what is bad for it. It would demonstrate the characteristics of best employees for that establishment. Accordingly, traditions which show the efficient methods for HRM functions would be the base for related strategy, so the policies. In other words, many times, past practices construct current activities and the future. So, the evaluations of HRM experiences facilitate productive implementations.

The history, traditions, and past practices of organizations also can be the source of resistance in implementing new strategies or any in changes of organizations or functions (Kane \& Palmer, 1995 cites from Dyer and Holder, 1988). In relation with this, Rosman et al. (2013) identified that; organizational culture is one of the main internal factors affecting the role of human resource department, which communicates organizational purposes, 
principles; and shapes the behaviors of personnel. Similarly, Mabey and Salaman (1995) affirm the significance of organizational culture for business functions.

\subsubsection{Priorities of Top Management}

The priorities of top management could be another source for HRM practices. Accordingly, internal promotion or promotion within the organization, demanded characteristics for the recruitment of new personnel, policies of wage and salary, relations with unions, breaking job contracts could all be shaped through the importance, which top management give them.

Some priorities can be as politics, professional behavior. Also, top management might pay attention to internal harmony, which leads efficiency, or profitability.

Mabey and Salaman (1995) point out the importance of shareholder priorities and management agendas on training and development activities. Buller (1988) found that, the skills and values of top management about HRM might be as one of the main factors affecting related strategies and policies. Equally, Rosman et al. (2013) achieved the result that, top management interference is one of the major internal components affecting HR department activities in health care sector.

\subsubsection{Priorities of Line Managers}

Line managers could put forward their priorities, which are in the same direction with firm strategies. First, they could have a priority of administrating their unit in an easy and efficient way. Therefore, line managers could demand employees who have complaisant characteristics that facilitate adoption. On the other hand, some managers put forward the creativity to recruit personnel, to be more innovative as a unit and as a firm, which leads competitive advantage.

It is also clear that; line managers should respond the necessities of their department, which also might structure HRM practices. In relation to this, Buller (1988) identifies that, line managers, strategy planners and HRM personnel are affecting each other. Similarly, Rosman and colleagues (2013) argued the fact that, managerial style is one the important elements shaping the policies HR department.

\subsubsection{Issues of Power and Politics}

Top management or unit managers might prefer HRM implementations, which let them gain power. Accordingly, they can promote anyone who is in favor of them, recruit personnel that could support them. Besides, educating, training and development opportunities could be given primarily to those who are in the same side with management. More than that, wage or salary practices can be a part of increasing performance through administrators' purposes with specific personnel.

Politics, in terms of principles to achieve strength, could shape any HRM function in an organization. In relation with this, relations with unions demonstrate the labor issues approach of a management. Furthermore, principles such as gender equality or inequality, implementations of wage and salaries, equity or imbalance of units which shows horizontal or vertical organizational structure, having or dismissing good relations with labor market institutions, are all the indicators of HR politics which can be a part of gaining power in an establishment.

Tsui and Milkovich (1987) examined and stressed the importance of power issues on human resource management activities. They examined the multiple constituency approach, and argued that power and policy issues affect HR practices.

\subsection{Impact of HRM Theory, Research and Writings}

As firms enlarge, the impacts of HRM theory, research and writings increases. This is because of the employment of high level, educated, qualified personnel. Accordingly, academic knowledge and information that were taken from universities or scientific books might shape the practices of HR functions. Equally, lessons taken from research findings can be taken as bases for any type of implementations.

Today, in Turkey there are almost 200 universities, which generally include departments of business or social sciences. These institutions generally collaborate with firms, in terms of consultancy to structure organizations; and to design and set up new projects. Therefore, scientific knowledge is a significant source for all business functions, so for HRM. Thus, Turkish companies increasingly benefit from academic studies; or from the work created by scholars. So, the internal and international success of Turkish firms should also be strongly related with this situation.

Also, youngsters get their university diplomas from abroad and work in national or international organizations. This facilitates to put universal knowledge into practice. 
Jain and Murray (1984) evaluated the related sub-title. As Kane and Palmer (1995) stated certification or grading, conferences, seminars, and lobbying activities might have significant impact on HRM policies and implementation.

\subsection{Impact of Education and Training in HRM}

The education and training of HR personnel clearly influences the frame of related activities. Accordingly, the skills and abilities of HRM employees or their expertise determines the methods and implementations of department. So, scientific methods are generally known or learnt in these units. Hence, the widely these types of instruments are used, the higher the organizational performances are.

As it was argued above, Turkish firms have highly qualified personnel in their functions, in HRM. These employees are both educated and trained internally, or employed from whom already are at these levels, in terms of skills and abilities.

\subsection{Impact of Overall HRM Strategy}

Business strategy is an important topic for organizations. Accordingly, companies tried to integrate all their functions to their organizational strategy. Thus, human resource strategy is being widely integrated to their business strategy by establishments to have a unified institution, in harmony. On the whole, the HRM strategy includes a macro perspective to HR issues focusing long term, and evaluating business environment. Equally, HR strategy should be consistent with organizational strategy, to be practiced successfully. In addition, HR managers should be a part of organizational strategy planning process.

HR strategy includes every type of evaluation of HR of an organization. Therefore, it can be expected that, all aspects of human resource issue should be considered, if HR activities are strategy based. In other words, if there is no HR strategy, then other factors can directly or indirectly influence HR actions.

\subsection{Cultural and Political Characteristics of Employees}

Every person carries his/her cultural background to organizations which he/she becomes a member. Therefore, cultural characteristics as tendencies to be a hard worker, adaptable, self oriented or cooperative can be significant factors affecting HRM practice. Equally, the feelings of belonging and loyalty, as assuming an organizational atmosphere like a home can increase personal and so organizational performance, are important dimensions or indicators. In other words, cultures that encourage cooperation could increase the outcomes of an establishment. Also, cultures those, which are exalting hard working behavior, would contribute organizational success.

Cultural characteristics differentiate. Therefore, firms use training and education to achieve a unified organizational culture, which orients and motivates members to accomplish purposes. In other words, cultural diversity makes companies spend effort to integrate them.

Some firms give importance to political backgrounds or approaches of their employees. Accordingly, these types of institutions generally operate in the bases of politics and for political purposes. So, they implement some of HRM functions depending on principles which have origins of politics. Moreover, promotion within an organization, or employing new personnel might also be realized through ideologies in those firms. In addition, the assessments of performance might be more tolerant to those who share the political ideologies of top management. In connection with this, others, who oppose the thought of top management, could work harder, not to be put out of that organization.

In the bases of knowledge above, the following hypothesis can be proposed:

First of all, the internal factors those affect HRM policies and practices, which are given above, are expected to be in correlation with external elements. To put it more simply, it is the requirement of consistency in policies and practices. In general, when an organization determines its strategies, all of the internal and external variables, their dimensions should be considered. Accordingly, this circumstance requires a comprehensive approach to both internal and external factors which have impacts on HRM activities. On the other hand, internal elements of HR are under the influence of external environmental elements. In other words, external factors construct internal structure. Therefore, a HR manager or expert should take all of the surrounding and structural elements into account.

Thus, it can be asserted that: Hypothesis 1 (H1): The internal factors which affect HRM policies and practices are positively associated with external variables that have same influences.

As it was stated above, a HR manager should behave consistently, and in a comprehensive way to succeed and create an efficient HRM practice. Hence, items that are considered in HRM planning and implementation 
process should reflect all of the dimensions related with the topic.

So, it can also be proposed that: Hypothesis 2 (H2): There is positive and statistically significant relation among environmental factors affecting HRM activities.

The size of organizations was examined as an internal environmental factor, above. On the other hand, in the frame of this paper, this research, "size" is also analyzed as a "demography" factor. Accordingly, it is investigated as an element that can change the level and number of internal and external environmental factors that have influence on HRM practices. It can be estimated that, larger firms might consider more internal and external environmental elements for a more sophisticated HRM system. It is clear that, it is more achievable for them when compared with a smaller firm, depending on their adequacy of resources. In other words, they can succeed and sustain more easily. Moreover, larger organizations can regulate internal elements more efficiently; and also can respond to external factors more effectively.

In Turkish practice, these discussed above are all can be seen. Today, Turkish large firms have global operations, especially in construction industry, in Middle East, Eastern Europe, Central Asia, and Caucasus. Equally, collaboration between Turkish firms and multinationals is so widespread, so company structures are also shaped due to the requirements of these types of links. In brief, local standards are integrated with global standards, especially in large firms.

Hence, it can be asserted that: Hypothesis 3 (H3): The size of organizations will be positively and significantly correlated with internal factors affecting HRM activities.

Hypothesis 4 (H4): The size of organizations will be positively and significantly correlated with external factors affecting HRM activities.

It is obvious that, public firms and private firms have mainly different purposes. Accordingly, in general, the priority of public organizations is to create social benefit, while private firms focusing on profitability and growth. On the other hand, both types of organizations should be competitive to survive in today's complicated business environment. Furthermore, in current situation, almost all the areas are open to private firms, and state firms are excluded from many sectors. In Turkey, after a declaration of Turkish Government in 2005; public firms were obliged to prepare their strategic plans to respond the requirements of turbulent business environment. Equally, it is clear that many private firms, especially large ones had already prepared their strategic plans until that term.

Environmental conditions or especially the academic literature on business management, and techniques that are presented, unify the structures and implementations of both public and private firms. In other words, same kinds of practices can be observed in both types of firms. This is the necessity of world business life today. On the whole, both internal and external environmental factors should be considered by either public or private firms in their HRM processes.

Therefore, it can be claimed that:

Hypothesis 5 (H5):

Hypothesis 5_0: The means of internal environmental factors would not change according to ownership type.

Hypothesis 5_1: The means of internal environmental factors would change according to ownership type.

Hypothesis 6 (H6):

Hypothesis 6_0: The means of external environmental factors would not change according to ownership type.

Hypothesis 6_1: The means of external environmental factors would change according to ownership type.

It is clear that, each industry has special characteristics. This is because of the special requirements of different structures, processes, inputs, and so outputs. So, it can be estimated that, the environmental factors which are considered by firms can be changed according to industries. Conversely, the common literature and the lectures of business schools create common bases for HRM implementation. In other words, industries loose their importance for human resource activities. This is because of the high competition in all areas of business life, and its requirement to fulfill industrial non-existences. In the same way, managerial methods which make establishments successful are taken as examples or road maps by other institutions. Besides, law and regulations have significant influence on the formation of HRM implementation. Moreover, management consultancy firms also guide companies, which unify the source of knowledge that schedules practice. On the whole, these show reasons behind the unification of HRM practices, which all can be observed widespread in Turkish business life.

Thus, it can be suggested that: 


\section{Hypothesis 7 (H7):}

Hypothesis 7_0: The means of internal environmental factors would not change according to industry type.

Hypothesis 7_1: The means of internal environmental factors would change according to industry type.

Hypothesis 8 (H8):

Hypothesis 8_0: The means of external environmental factors would not change according to industry type.

Hypothesis 8_1: The means of external environmental factors would change according to industry type.

Cities are not only areas in which cultures and civilizations are reflected, but also they provide suitable infrastructure for organizations. In fact, every city has a culture that is shaped mostly by geography, size, economy, education system, history, and religion. Equally, when cities become larger, cultures become more similar. To put it more simply, especially metropolises present similar opportunities to organizations that shape business functions. Furthermore, connections between cities, and by the help of communication technologies the urban world has been globalised. Therefore, infrastructure was become more homogeneous. Thus, cultures are unified. Besides, technology became more common too.

Hence, it can be claimed that:

Hypothesis 9 (H9):

Hypothesis 9_0: The means of internal environmental factors would not change according to city of firm headquarters.

Hypothesis 9_1: The means of internal environmental factors would change according to city of firm headquarters.

Hypothesis 10 (H10):

Hypothesis 10_0: The means of external environmental factors would not change according to city of firm headquarters.

Hypothesis 10_1: The means of external environmental factors would change according to city of firm headquarters.

\section{Methodology}

\subsection{Research Goal}

In this survey it was aimed to identify the role and affection levels of possible internal and external factors on HRM activities, which were considered by HR managers of firms. Moreover, it was also aimed to demonstrate the relationship or fit among internal and external elements that have impact on HRM. Finally, the relationships between size, sector, ownership type, origin country, city of headquarters and internal or external environmental factors were also intended to reveal. The ultimate goal of this paper is mainly to set light on the environmental factors - HRM relationship under the hypothesis developed and to contribute knowledge base for managers with some suggestions.

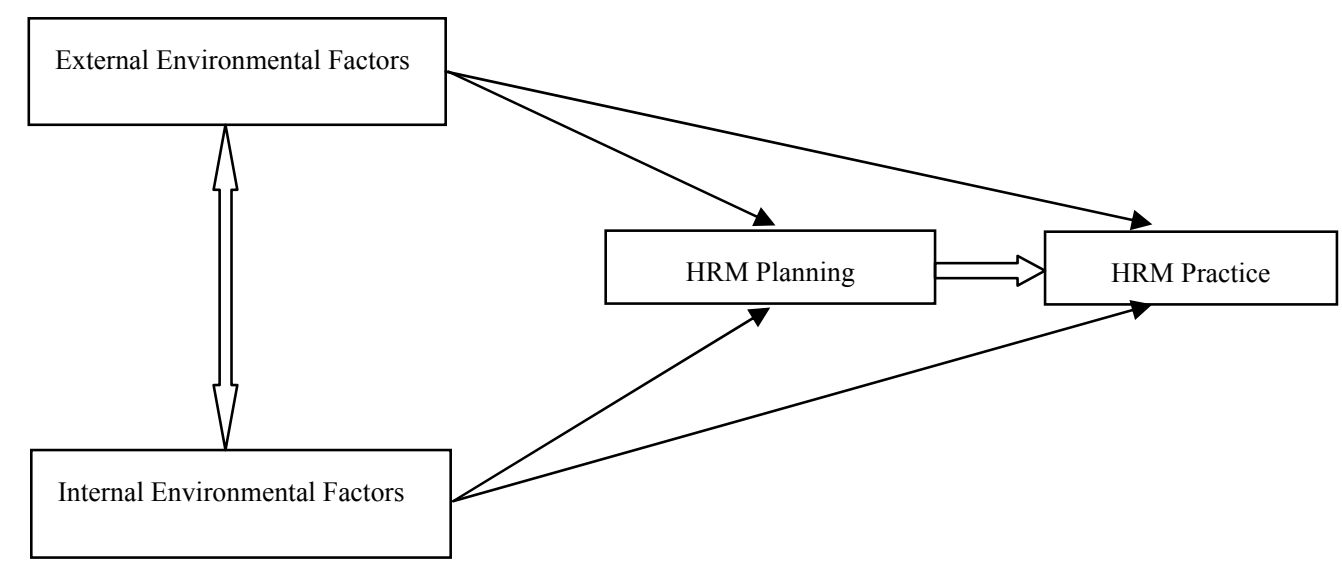

Figure 1. Research model for environmental factors - human resource planning, practice relation 


\subsection{Sample and Data Collection}

To test the hypotheses developed between the couples of variables, a questionnaire as a method of data collection was conducted on a total of top 500 large firms of Turkey, between January to March 2012. The survey forms were firstly sent by e-mail. Then, due to very limited response rate, it was decided to send them by mail. Accordingly, survey forms, and a stamp affixed and address written envelope were put in an envelope and sent. The questionnaire included a total of 26 items using 5-point Likert Scale. Also, survey form included 6 demographical questions. After conducting a pilot test on a group of 30 firms, it was decided to continue with the rest of the questionnaires, on the same sample. Data obtained from those 79 questionnaires analysed through the SPSS statistical package program, and 12 possible relations were tested.

The participants were from different sectors: 56 (70.9\%) manufacturing, 2 (2.5\%) mining, 15 (19\%) food, 4 (5.1\%) energy, and 2 (2.5) construction firms; as a total of 79 firms. The year of foundation changes between 1933 and 2007. Companies that are in the sample have headquarters in 23 different cities or provinces of Turkey. Accordingly, 24 of them (30.4\%) have headquarters in Istanbul, 8 of them (10.1\%) have headquarters in Izmir, 7 of them (8.9) have headquarters in Bursa, 6 of them (7.6\%) have headquarters in Gaziantep. In addition, Ankara, Kayseri, and Manisa provinces host 4 headquarters (5.1\%) each; and $15.3 \%$ in total. So, $27.7 \%$ of firms are located in some other provinces (Ordu, Adana, Konya, Sakarya, Kayseri, Malatya, Bolu, Kocaeli, Zonguldak, etc.). The ownership types of firms are: 5 of establishments (6.3\%) are public firm, and 74 of them (93.7\%) are private firms. On the other hand, in terms of the country of origin, 68 companies $(86.1 \%)$ are Turkish, 8 of firms $(10.1 \%)$ are owned by foreigners, and 3 of them (3.8\%) are joint ventures. Finally, as the "size" of organizations was taken as the number of employees, there were 27 firms which have less than 500 employees. 23 companies have employees changing from 500 to 1000 . Moreover, 23 firms have more than 1000 and less than 5000 employees. Also, 6 firms have more than 5000 employees.

\subsection{Analysis and Results}

A total of 26 items included in the questionnaire are grouped under 7 variables. The variable of "the impact of law and employees" is measured by 4 items, that of "the impact of literature and experiences" by 5 items, that of "the impact of culture and politics" by 4 items, "the impact of change" by 3 items, "the impact of actions" by 3 items, "the impact of priorities" by 2 items, and that of "the impact of structure and strategy" by 2 items. According to the reliability tests conducted on these 7 variables, all the scales are found to be reliable (Cronbach's Alpha $>0.70$ ). In order to test the content validity of the scales used, the views by 4 academics from the same university were taken, and all the scales are also found to be valid by a mean of ,90 agreement points by these academics.

Table 1 . The results of factor and reliability analysis

\begin{tabular}{|c|c|c|c|c|}
\hline & Factor $(\mathrm{KMO}=.713 ; .000)$ & Value & Alpha & $\%$ Variance \\
\hline & The Impact of Law and Employees & & & \\
\hline $\mathrm{H} 12$ & Legislation/Regulation & .774 & .8442 & 13.841 \\
\hline H11 & Industry/Sector characteristics & .774 & & \\
\hline $\mathrm{H} 32$ & Qualities of employees & .718 & & \\
\hline \multirow[t]{2}{*}{$\mathrm{H} 18$} & Size of the organization & .677 & & \\
\hline & The Impact of Literature and Experiences & & & \\
\hline $\mathrm{H} 26$ & The impact of professional organizations & .838 & .8274 & 13.578 \\
\hline $\mathrm{H} 28$ & HRM staff's experiences in other organizations & .706 & & \\
\hline $\mathrm{H} 24$ & The impact of HRM theory, research and writings & .686 & & \\
\hline $\mathrm{H} 25$ & The impact of education and training in HRM & .678 & & \\
\hline \multirow[t]{2}{*}{$\mathrm{H} 17$} & Political daily developments in Turkey & .566 & & \\
\hline & The Impact of Culture and Politics & & & \\
\hline $\mathrm{H} 31$ & Cultural /political characteristics of managers & .849 & .8411 & 12.014 \\
\hline $\mathrm{H} 30$ & Cultural/political characteristics of employees & .805 & & \\
\hline
\end{tabular}




\begin{tabular}{|c|c|c|c|c|}
\hline $\mathrm{H} 23$ & Issues of power and politics & .757 & & \\
\hline \multirow[t]{2}{*}{$\mathrm{H} 29$} & General Education policies and practices in Turkey & .587 & & \\
\hline & The Impact of Change & & & \\
\hline $\mathrm{H} 7$ & Changes in international economy & .829 & .7622 & 10.506 \\
\hline H9 & Changes in national economy & .772 & & \\
\hline \multirow[t]{2}{*}{$\mathrm{H} 8$} & Changes in technology & .658 & & \\
\hline & The Impact of Actions & & & \\
\hline H13 & Actions of unions & .774 & .6865 & 8.304 \\
\hline H14 & Actions of competitors & .650 & & \\
\hline \multirow[t]{2}{*}{$\mathrm{H} 20$} & History/traditions/past practice & .564 & & \\
\hline & The Impact of Priorities & & & \\
\hline $\mathrm{H} 21$ & Priorities of top management & .841 & .6796 & 7.814 \\
\hline \multirow[t]{2}{*}{$\mathrm{H} 22$} & Priorities of line managers & .748 & & \\
\hline & The Impact of Structure and Strategy & & & \\
\hline H19 & Organizational structure & .648 & .7757 & 7.183 \\
\hline $\mathrm{H} 27$ & Impact of an overall HRM strategy & .614 & & \\
\hline
\end{tabular}

The results of factor analysis revealed seven factors. Besides, the reliability analysis showed that the scale was reliable $($ Alpha $=.9035)$. According to the factor analysis there are seven types of dimensions achieved. These are, "the impact of law and employees", "the impact of literature and experiences", "the impact of culture and politics", "the impact of change", "the impact of actions", "the of priorities" and "the impact of structure and strategy".

As it can be seen on Table 2, the factors affecting HRM activities are in the following order: "The priorities of top management" has a mean of 4.24 , which is the highest. Accordingly, this result shows that the priorities of top management are the most important factor affecting HRM practices. In other words, HR managers give more importance to this element. The second factor is the related law or legislation/regulation (4.21). The changes in national economy (4.13) and the qualities of employees (4.13) are at the same ranking. Also, organizational strategy/purposes (4.08) (excluded), industry characteristics (4.07), size of the organization (4.05), changes in technology (4.0385), organizational mission/vision (4.0380) (excluded), and organizational structure (4.01) have means over 4.

The second group includes "change in the international economy" (3.84), impact of an overall HRM strategy (3.84), history/traditions/past practice (3.78), impact of education and training in HRM (3.75), actions of competitors (3.70), priorities of line managers (3.64), HRM theory, and research and literature (3.54), and general education policies and practices in Turkey (3.54).

The third group includes items which has values under 3.5. Accordingly, these are national culture (3.37) (excluded), issues of power and politics (3.37), professional organizations/consultancy firms (3.35), cultural/political characteristics of managers (3.32), political developments in Turkey (3.25), actions of unions (3.22), cultural/political characteristics of employees (3.10), HRM staff's experiences in other organizations (2.98). 
Table 2. Descriptive statistics about factors affecting HRM

\begin{tabular}{|c|c|c|c|c|c|}
\hline & Factors (Alpha .9035) & Mean & $\begin{array}{l}\text { Standard } \\
\text { Error }\end{array}$ & Std. Deviation & Variance \\
\hline H21 & Priorities of top management & 4.2405 & .1023 & .9089 & .826 \\
\hline H12 & Legislation/Regulation & 4.2152 & .1106 & .9828 & .966 \\
\hline H9 & Changes in national economy & 4.1392 & .1321 & 1.1738 & 1.378 \\
\hline H32 & Qualities of employees & 4.1392 & .1107 & .9836 & .968 \\
\hline H16E & Organizational strategy/purpose (Excluded) & 4.0886 & .1128 & 1.0024 & 1.005 \\
\hline H11 & Industry/Sector characteristics & 4.0759 & .1122 & .9971 & .994 \\
\hline H18 & Size of the organization & 4.0506 & .1094 & .9727 & .946 \\
\hline H8 & Changes in technology & 4.0385 & .1160 & 1.0249 & 1.050 \\
\hline H15E & Organizational mission/vision (Excluded) & 4.0380 & .1088 & .9667 & .934 \\
\hline H19 & Organizational structure & 4.0127 & .1058 & .9405 & .884 \\
\hline H7 & Changes in international economy & 3.8481 & .1349 & 1.1992 & 1.438 \\
\hline H27 & Impact of an overall HRM strategy & 3.8481 & .1183 & 1.0511 & 1.105 \\
\hline H20 & History/Traditions/Past Practice & 3.7848 & .1307 & 1.1621 & 1.351 \\
\hline H25 & Impact of education and training in HRM & 3.7595 & .1277 & 1.1347 & 1.288 \\
\hline H14 & Actions of competitors & 3.7089 & .1276 & 1.1340 & 1.286 \\
\hline H22 & Priorities of line managers & 3.6456 & .1182 & 1.0505 & 1.104 \\
\hline H24 & HRM theory, research and literature & 3.5443 & .1309 & 1.1635 & 1.354 \\
\hline H29 & General education policies and practices in Turkey & 3.5443 & .1321 & 1.1745 & 1.379 \\
\hline H10E & National culture (Excluded) & 3.3797 & .1376 & 1.2227 & 1.495 \\
\hline $\mathbf{H 2 3}$ & Issues of power and politics & 3.3797 & .1387 & 1.2331 & 1.521 \\
\hline H26 & Professional organizations/Consultancy firms & 3.3544 & .1453 & 1.2914 & 1.668 \\
\hline H31 & Cultural/Political characteristics of managers & 3.3291 & .1493 & 1.3274 & 1.762 \\
\hline H17 & Political developments in Turkey & 3.2532 & .1424 & 1.2656 & 1.602 \\
\hline H13 & Actions of unions & 3.2278 & .1680 & 1.4931 & 2.229 \\
\hline H30 & Cultural/Political characteristics of employees & 3.1013 & .1503 & 1.3358 & 1.784 \\
\hline H28 & HRM staff's experiences in other organizations & 2.9873 & .1447 & 1.2860 & 1.654 \\
\hline
\end{tabular}

Due to the fact that, the data did not show normal distribution for the variables $\mathrm{C} 1, \mathrm{C} 4$, and $\mathrm{C}$, they were transformed to achieve normal distribution. Then, a correlation analysis was conducted with the continual variables obtained from factor analysis, as some of them transformed.

Table 3. Correlation results among variables

\begin{tabular}{|c|c|c|c|c|c|c|c|}
\hline & $\mathrm{C} 1$ & $\mathrm{C} 2$ & $\mathrm{C} 3$ & $\mathrm{C} 4$ & $\mathrm{C} 5$ & $\mathrm{C6}$ & $\mathrm{C} 7$ \\
\hline C1. Law and Employees & 1.000 & & & & & & \\
\hline \multirow[t]{2}{*}{ C2. Literature and Experiences } & $.376^{* *}$ & 1.000 & & & & & \\
\hline & .001 & & & & & & \\
\hline \multirow[t]{2}{*}{ C3. Culture and Politics } & $.459^{* *}$ & $.482 * *$ & 1.000 & & & & \\
\hline & .000 & .000 & & & & & \\
\hline \multirow[t]{2}{*}{ C4. Change } & $.332 * *$ & $.306^{* *}$ & $.342 * *$ & 1.000 & & & \\
\hline & .003 & .006 & .002 & & & & \\
\hline \multirow[t]{2}{*}{ C5. Actions } & $.399 * *$ & $.401 * *$ & $.364 * *$ & $.433 * *$ & 1.000 & & \\
\hline & .000 & .000 & .001 & .000 & & & \\
\hline \multirow[t]{2}{*}{ C6. Priorities } & $.279^{*}$ & $.224 *$ & $.303 * *$ & .124 & .220 & 1.000 & \\
\hline & .013 & .047 & .007 & .278 & .052 & & \\
\hline \multirow[t]{2}{*}{ C7. Structure and Strategy } & $.552 * *$ & $.427 * *$ & $.339 * *$ & $.452 * *$ & $.515^{* *}$ & $.246^{*}$ & 1.000 \\
\hline & .000 & .000 & .002 & .000 & .000 & .029 & \\
\hline
\end{tabular}

Note. ${ }^{* *}$ Correlation is significant at 0.01 level. ${ }^{*}$ Correlation is significant at 0.05 level. (2-tailed). $\mathrm{N}=79$.

As it can be seen from Table 3, environmental factors are significantly and positively correlated with each other. Accordingly, "the impact of law and employees" is associated with the impacts of "literature and experiences" $(.376 ; .001)$, "culture and politics" $(.459 ; .000)$, "change" (.332; .003), "actions" (.399; .000), "priorities" 
$(.279 ; .013)$, "structure and strategy" $(.552 ; .000)$. Similarly, "the impact of literature and experiences" is significantly correlated with "culture and politics" (.482; .000), "change" (.306; .006), "actions" (.401; .000), "priorities" $(.224 ; .047)$, "structure and strategy" $(.427 ; .000)$. Equally, "the impact of culture and politics" is positively associated with the impact of "change" $(.342 ; .002)$, "actions" $(.364 ; .001)$, "priorities" (.303; .007), and "structure and strategy" $(.339 ; .002)$. Moreover, "the impact of change" is positively and significantly correlated with the impact of "actions" $(.433 ; .000)$, and "strategy and structure" $(.452 ; .000)$. In addition, "the impact of actions" is significantly related with "the impact of structure and strategy" $(.515 ; .000)$. Finally, "the impact of priorities" is positively associated with "the impact of structure and strategy" (.246; .029).

The results of correlation analysis support the claim that "there is positive and statistically significant relationship among environmental factors affecting HRM activities" (Hypothesis 2).

Table 4. Correlations between size, internal and external factors

\begin{tabular}{llll}
\hline & H6 & Int34 & Ext35 \\
\hline H6. Size & 1.000 & & \\
Int34. Internal Factors & .129 & 1.000 & \\
& .257 & & \\
Ext35. External Factors & -.028 & $.678^{* *}$ & 1.000 \\
& .804 & .000 & \\
\hline
\end{tabular}

Note. ${ }^{*}$ Correlation is significant at the 0.01 level (2-tailed). $\mathrm{N}=79$.

As it can be seen from Table 4, the mean of internal factors affecting HRM activities is positively and significantly correlated with the mean of external factors which has the same type of influence $(.678 ; .000)$. Therefore, the Hypothesis 1 (H1) is accepted. Similarly, this result also supports the Hypothesis 2 (H2), which was discussed above, and claims the presence of positive and statistically significant relationship among environmental factors affecting HRM activities.

Besides, Table 4 demonstrates that, the sizes of organizations are not significantly associated with internal factors that affect HRM. In other words, the findings do not support the claim in Hypothesis 3 (H3). Equally, the sizes of organizations are not positively and significantly correlated with external factors which have impacts on HRM. So, Hypothesis 4 (H4) is also not supported.

Hypothesis 5 (H5):

Hypothesis 5_0: The means of internal environmental factors would not change according to ownership type.

Hypothesis 5_1: The means of internal environmental factors would change according to ownership type.

Hypothesis 6 (H6):

Hypothesis 6_0: The means of external environmental factors would not change according to ownership type.

Hypothesis 6_1: The means of external environmental factors would change according to ownership type.

Table 5. The result of test of homogeneity of variances

\begin{tabular}{llll}
\hline Levene Statistic & df1 & Df2 & Sig. \\
\hline 1,520 & 1 & 77 & .221 \\
\hline
\end{tabular}

Table 5 shows the result of the basic assumption of one-way ANOVA. The p value here (sig.) is bigger than 0.05 , which is .221. According to this result, it can be said that variances are homogeneous. Therefore, it also can be estimated that, the results of variance analysis will be dependable. 
Table 6. The result of one-way variance analysis (ANOVA) tests

\begin{tabular}{llllll}
\hline & Sum of Squares & df & Mean Square & F & Sig. \\
\hline Between Groups & $1.171 \mathrm{E}-02$ & 1 & $1.171 \mathrm{E}-02$ & .022 & .882 \\
Within Groups & 40.465 & 77 & .526 & & \\
Total & 40.477 & 78 & & & \\
\hline
\end{tabular}

Table 6, demonstrates the one-way ANOVA results related with Hypothesis 5. As, p (sig.) value is bigger than 0.05 , the $\mathrm{H}_{0}$ is accepted. That is to say, the means of internal environmental factors would not change according to ownership type.

Hypothesis 6 (H6):

Hypothesis $6 \_0$ : The means of external environmental factors would not change according to ownership type.

Hypothesis $6 \_1$ : The means of external environmental factors would change according to ownership type.

Table 7. The Result of test of homogeneity of variances

\begin{tabular}{llll}
\hline Levene Statistic & df1 & Df2 & Sig. \\
\hline .014 & 1 & 77 & .907 \\
\hline
\end{tabular}

Table 7 shows the result of the basic assumption of one-way ANOVA. The p value here (sig.) is bigger than 0.05 , which is .907 . According to this result, it can be said that variances are homogeneous. Therefore, it also can be estimated that, the results of variance analysis will be dependable.

Table 8 . The result of one-way variance analysis (ANOVA) tests

\begin{tabular}{llllll}
\hline & Sum of Squares & df & Mean Square & F & Sig. \\
\hline Between Groups & .385 & 1 & .385 & .776 & .381 \\
Within Groups & 38.209 & 77 & .496 & & \\
Total & 38.594 & 78 & & & \\
\hline
\end{tabular}

Table 8, demonstrates the one-way ANOVA results related with Hypothesis 6. As, p (sig.) value is bigger than 0.05 , the $\mathrm{H}_{0}$ is accepted. That is to say, the means of external environmental factors would not change according to ownership type.

Hypothesis 7 (H7):

Hypothesis 7_0 : The means of internal environmental factors would not change according to industry type.

Hypothesis 7_1: The means of internal environmental factors would change according to industry type.

Table 9. The result of test of homogeneity of variances

\begin{tabular}{llll}
\hline Levene Statistic & $\mathrm{df} 1$ & $\mathrm{df} 2$ & Sig. \\
\hline 1.720 & 4 & 74 & .155 \\
\hline
\end{tabular}

Table 9 shows the result of the basic assumption of one-way ANOVA. The p value here (sig.) is bigger than 0.05 , which is .155 . According to this result, it can be said that variances are homogeneous. Therefore, it also can be estimated that, the results of variance analysis will be dependable.

Table 10. The result of one-way variance analysis (ANOVA) tests

\begin{tabular}{|c|c|c|c|c|c|}
\hline & $\begin{array}{l}\text { Sum } \\
\text { Squares }\end{array}$ & of $\quad d f$ & Mean Square & $\mathbf{F}$ & Sig. \\
\hline Between Groups & 2.086 & 4 & .521 & 1.005 & .410 \\
\hline Within Groups & 38.391 & 74 & .519 & & \\
\hline Total & 40.477 & 78 & & & \\
\hline
\end{tabular}


Table 10, demonstrates the one-way ANOVA results related with Hypothesis 7. As, $\mathrm{p}$ (sig.) value is bigger than 0.05 , the $\mathrm{H}_{0}$ is accepted. That is to say, the means of internal environmental factors would not change according to industry type.

Hypothesis 8:

Hypothesis $8 \_0$ : The means of external environmental factors would not change according to industry type.

Hypothesis $8 \_1$ : The means of external environmental factors would change according to industry type.

Table 11. The result of test of homogeneity of variances

\begin{tabular}{llll}
\hline Levene Statistic & df1 & df2 & Sig. \\
\hline 2.135 & 4 & 74 & .085 \\
\hline
\end{tabular}

Table 11 shows the result of the basic assumption of one-way ANOVA. The $p$ value here (sig.) is bigger than 0.05 , which is .085 . According to this result, it can be said that variances are homogeneous. Therefore, it also can be estimated that, the results of variance analysis will be dependable.

Table 12. The result of one-way variance analysis (ANOVA) tests

\begin{tabular}{llllll}
\hline & Sum of Squares & df & Mean Square & F & Sig. \\
\hline Between Groups & .986 & 4 & .246 & .485 & .747 \\
Within Groups & 37.608 & 74 & .508 & & \\
Total & 38.594 & 78 & & & \\
\hline
\end{tabular}

Table 12, demonstrates the one-way ANOVA results related with Hypothesis 8. As, $\mathrm{p}$ (sig.) value is bigger than 0.05 , the $\mathrm{H}_{0}$ is accepted. That is to say, the means of external environmental factors would not change according to industry type.

Hypothesis 9 (H9):

Hypothesis 9_0: The means of internal environmental factors would not change according to the city of firm headquarters.

Hypothesis 9_1: The means of internal environmental factors would change according to the city of firm headquarters.

Table 13. The result of test of homogeneity of variances

\begin{tabular}{llll}
\hline Levene Statistic & df1 & df2 & Sig. \\
\hline 1.601 & 21 & 57 & .082 \\
\hline
\end{tabular}

Table 13 shows the result of the basic assumption of one-way ANOVA. The p value here (sig.) is bigger than 0.05 , which is .082 . According to this result, it can be said that variances are homogeneous. Therefore, it also can be estimated that, the results of variance analysis will be dependable.

Table 14. The result of one-way variance analysis (ANOVA) tests

\begin{tabular}{llllll}
\hline & Sum of Squares & df & Mean Square & F & Sig. \\
\hline Between Groups & 10.468 & 21 & .498 & .947 & .537 \\
Within Groups & 30.008 & 57 & .526 & & \\
Total & 40.477 & 78 & & & \\
\hline
\end{tabular}

Table 14, demonstrates the one-way ANOVA results related with Hypothesis 9. As, p (sig.) value is bigger than 0.05 , the $\mathrm{H}_{0}$ is accepted. That is to say, the means of internal environmental factors would not change according to the city of firm headquarters. 
Hypothesis 10 (H10):

Hypothesis 10_0: The means of external environmental factors would not change according to the city of firm headquarters.

Hypothesis 10_1: The means of external environmental factors would change according to the city of firm headquarters.

Table 15. The result of test of homogeneity of variances

\begin{tabular}{llll}
\hline Levene Statistic & df1 & df2 & Sig. \\
\hline 1.239 & 21 & 57 & .256 \\
\hline
\end{tabular}

Table 15 shows the result of the basic assumption of one-way ANOVA. The p value here (sig.) is bigger than 0.05 , which is .256 . According to this result, it can be said that variances are homogeneous. Therefore, it also can be estimated that, the results of variance analysis will be dependable.

Table 16. The result of one-way variance analysis (ANOVA) tests

\begin{tabular}{llllll}
\hline & Sum of Squares & df & Mean Square & F & Sig. \\
\hline Between Groups & 14.904 & 21 & .710 & 1.708 & .057 \\
Within Groups & 23.690 & 57 & .416 & & \\
Total & 38.594 & 78 & & & \\
\hline
\end{tabular}

Table 16, demonstrates the one-way ANOVA results related with Hypothesis 10. As, p (sig.) value is bigger than 0.05 , the $\mathrm{H}_{0}$ is accepted. That is to say, the means of external environmental factors would not change according to the city of firm headquarters.

\section{Discussion}

The results of the research reveal that "priorities of top management" is the most important factor affecting HRM activities. Equally, "legislation/regulation", "changes in the national economy", "qualities of employees", "industry/sector characteristics", "size of the organization", "changes in the technology", and "organizational structure" are other high ranking factors affecting the HR practices, which have a mean of below 4.

It is clear that top management priorities are the elements that are considered at the first hand. This result shows the importance and effectiveness of top management in organizations. Similarly, legislation is also a necessity that every institution has to take into account and obey. Therefore, these two findings reflect the reality that, establishments experienced. On the other hand, changes in the national economy directly or indirectly affect any function of a firm. So, again it should be considered, and should be responded effectively. Similarly, "industry/sector characteristics" also shapes business functions. At the same time, the "qualities of employees" is an important variable that to determine the frame of HRM activities. Moreover, "the size of the organization", and "organizational structure" are among the internal factors that the management of Turkish large firms give priority while deciding their HRM plans and implementing it.

The "impact of an overall HRM strategy" is considered in a high-moderate level. Accordingly, this shows that "strategy" is an important variable which structures the HRM practices of Turkish firms, which are in the frame of the sample. Equally, as it is expected, companies in the sample, have a strategic view for this function. In relation with this, it is clear that, the "history/traditions/past practice" of firms, "the impact of education and training in HRM", "HRM theory, research and literature", and "general education policies and practices in Turkey" provide bases for that "strategy". Similarly, the "actions of competitors" supports strategic analysis as an external element, in moderate level.

It is a striking result that, "the issues of power and politics" is not an important element for decision makers of HRM. Similarly, the "cultural/political characteristics of managers", and the "cultural/political characteristics of employees" are considered in a low level. So, these can be indicators of a peaceful organizational climate that generally successful organizations have. On the other hand, the impact of "professional organizations/consultancy firms" is also a relatively "not usually" considered element. Accordingly, it can be said that, these large firms have powerful, expert, complicated, and sophisticated HRM departments that, they rarely need consultancy from professional organizations. Finally, the "HRM staff's experiences in other 
organizations" gets the lowest mark, that supports the previous result.

The results revealed that, internal and external environmental factors are significantly associated. Similarly, it was found that, variables are significantly correlated. This reflects a positive situation for the scale. Also, it demonstrates how interrelated the variables are. On the other hand, it was achieved that, there is no relation between size and environmental factors. This implies that, similar organizations have similar implementations.

The results of data analysis also revealed that, there is no link between internal or external environmental factors that have impact on HRM activities, and ownership type, industry type or the city of firm headquarters. Accordingly, these findings can be related to the equivalence of organizations that are in the sample. To put it more simply, these companies act through the guidance of scientific knowledge, which unifies their responses to current business requirements. In other words, these institutions behave in the frame of an analytical approach to business functions. Therefore, size, ownership type, industry type or the city of headquarters does not change their consideration for HRM related environmental elements. On the other hand, these findings also demonstrate how similar the environmental dimensions, which organizations confront, are. In other words, this situation reflects how business life consists of same kinds of conditions for different types of industries.

\section{Conclusion}

This paper has investigated the environmental factors affecting HRM policies and practices of Turkish large firms; and, has shown that companies take these internal and external elements into consideration in a high or at least moderate level in general. It was also shown that the internal and external environmental factors are mostly positively and significantly associated. The results of this research supported the hypotheses, which propose no positive and significant relationship between industries, city of headquarter, ownership type, country of origin and internal and external environmental factors. At the same time, it was also seen that, the sizes of organizations are associated with environmental elements, which are taken into account during HRM processes. In general, therefore, it seems that further researches are needed to test the impacts of the more environmental factors on HRM strategies, policies, and implementations.

This study has found that the HR managements of Turkish large firms generally take many environmental factors into account. Moreover, Turkish firms consider or being affected both internal and external elements of organizational environment, when determining HR policies. Also, the impact of an overall HRM strategy is one of the high ranking elements that shape HR actions of these companies; which shows that, these institutions generally have strategies for their HR activities. Consequently, these findings reflect the current reality that, business environments becoming more complex day by day, that should be considered effectively. In other words, the number of environmental elements increases, and they are changing in a fast way.

Further investigation should be realized with more environmental factors, with a larger sample. Furthermore, organizations of different countries should be compared for their environmental system that shape HR planning and implementations. This research will serve as a base for future studies and encourage associating and searching the relationships of the environmental factors, with their HRM practices. This research has thrown up many questions in need of further investigation. The current study found no relationship between dependent and independent variables. So, further work needs to be done to determine the related association in details, on different kinds of samples, in different countries.

This study may enhance the understanding of the environmental factors and extend the concept while relating it with the HRM practice. Although the results have not supported some of the previsions, the attempt to control and consider all of the environmental elements should be continued.

\section{References}

Barney, J. B. (1991). Firm Resources and Sustained Competitive Advantage. Journal of Management, 17(1), 99-120.

Barney, J. B. (1995). Looking Inside for Competitive Advantage. Academy of Management Executive, 9(4), 49-61.

Barney, J. B., \& Wright, P. M. (1997). On Becoming a Strategic Partner: The Role of Human Resources in Gaining Competitive Advantage. Human Resource Management, 37(1), 31-46.

Bart, C. K., \& Baetz, M. C. (1998). The Relationship Between Mission Statements and Firm Performance: an Expletory Study. Journal of Management Studies, 35(6), 823-853.

Bartkus, B. R., Glassman, M., \& Mcafee, R. B. (2002). Do Large European, US and Japanese Firms Use Their Web Sites to Communicate Their Mission? European Management Journal, 20(4), 423-429. 
Bartkus, B. R., Glassman, M., \& Mcafee, R. B. (2004). A Comparison of the quality of European, Japanese, and U.S. mission statements: A content analysis. European Management Journal, 22(4), 393-401.

Buller, P. F. (1988). Successful Partnership: HR and Strategic Planning at Eight Top Firms. Organizational Dynamics, 17(2), 27-43.

Bingöl, D. (2006). Insan Kaynakları Yönetimi (6th ed.). Istanbul: Arıkan.

Cascio, W. F. (1993). Downsizing: What Do We Know? What Have We Learned? Academy of Management Executive, 7(1), 95-104.

Chandrakumara, A., \& Sparrow, P. (2004). Work Orientation as an Element of National Culture and Its Impact on HRM Policy-Practice Design Choices. International Journal of Manpower, 25(6), 564-589.

DeFillippi, R. J. (2002). Organizational Models for Collaboration in New Economy. Human Resource Planning, 25(4), 7-18.

Delery, J. E., \& Doty, H. (1996). Modes of Theorizing in Strategic Human Management: Test of Universalistic, Contingency, and Configurational Performance Predictions. Academy of Management Journal, 39(4), 802-835.

Jackson, S. E., Schuler, R. S., \& Rivero, J. C. (1989). Organizational Characteristics as Predictors of Personnel Practices. Personnel Psycology, 42, 727-786.

Jain, H., \& Murray, V. (1984). Why the Human Resources Management Function Fails. California Management Review, 26(4), 95-110.

Kane, B., \& Palmer, I. (1995). Strategic HRM or Managing the Employment Relationship. International Journal of Manpower, 16(5/6), 6-21.

Kabene, S. M., Orchard, C., Howard, J. M., Soriano, M. A., \& Leduc, R. (2006). The Importance of Human Resources Management in Health Care: A Global Context. Human Resources for Health, 4(20), 1-17. http://dx.doi.org/10.1186/1478-449I-4-20.

Mabey, C., \& Salaman, G. (1995). Strategic Human Resource Management. Great Britain: Blackwell.

Mello, J. A. (2006). Strategic Human Resource Management (2nd ed.). Ohio, United States: Thompson, South-Western.

Miles, R. E., \& Snow, C. C. (1984). Designing Strategic Human Resource Systems. Organizational Dynamics, $13,36-52$.

Mintzberg, H., Lampel, J., Quinn, J. B., Ghoshal, S. (2003). The Strategy Process (4th ed.). Essex, United Kingdom: Pearson Education Limited.

Powell, G. N. (1990). One More Time: Do Female and Male Managers Differ? Academy of Management Executive, 4(3), 68-75.

Rosenzweig, P. M., \& Nohria, N. (1994). Influences on Human Resources Management Practices in Multinational Corporations. Journal of International Business Studies (2nd Quarter).

Rosman, Md. Y., Shah, F. A., Hussain, J., \& Hussain, A. (2013). Factors Affecting the Role of Human Resource Department in Private Healthcare Sector in Pakistan: A Case Study of Rehman Medical Institute (RMI). Research Journal of Recent Studies, 2(1), 84-90.

Schuler, R. S. (1990). Repositioning the Human Resource Function: Transformation or Demise? Academy of Management Executive, 4(3), 49-60.

Schuler, R. S., \& Jackson, S. E. (1989). Determinants of Human Resource Management Priorities and Implications for Industrial Relations. Journal of Management, 15(1), 89-99.

Sparrow, P., Randall, S., Schuler, R. S., \& Jackson, S. E. (1994). Convergence or Divergence: Human Resource Practices and Policies for Competitive Advantage Worldwide. The International Journal of Human Resource Management, 5(2), 267-299.

Steffy, B., \& Maurer, S. (1988). Conceptualizing and Measuring the Effectiveness of Human Resource Activities. Academy of Management Revies, 13, 271-286.

Terpstra, D. E., \& Rozell, E. J. (1993). The Relationship of Staffing Practices to Organizational Level Measures of Performance. Personnel Psychology, 46, 27-48.

Tiwari, P., \& Saxena, K. (2012). Human Resource Management Practices: A Comprehensive Review. Pakistan 
Business Review, January.

Truss, C., \& Gratton, L. (1994). Strategic Human Resource Management : A Conceptual Approach. The International Journal of Human Resource Management, 5(3), 663-686.

Tsui, A. S., \& Milkovich, G. T. (1987). Personnel Department Activities: Constituency Perspectives and Preferences. Personnel Psycology, 40, 519-537.

Ulrich, D. (1998). A New Mandate for Human Resources. USA: Harvard Business School.

Wheelen, T. L., \& Hunger, J. D. (2002). Strategic Management and Business Policy (8th ed.). New Jersey, USA: Prentice Hall, Pearson Education International Inc.

Wright, P. M., \& McMahan, G. C. (1992). Theoretical Perspectives of Strategic Human Resource Management. Journal of Management, 18(1), 295-320.

Wright, P. M., McMahan, G. C., \& McWilliams, A. (1994). Human Resources and Sustained Competitive Advantage: A Resource-Based View. International Journal of Human Resource Management, 5(2), 301-326.

Wright, P., Kroll, M. J., \& Parnell, J. A. (1998). Strategic Management, Concepts and Cases. New Jersey, USA: Prentice-Hall, Inc.

\section{Copyrights}

Copyright for this article is retained by the author(s), with first publication rights granted to the journal.

This is an open-access article distributed under the terms and conditions of the Creative Commons Attribution license (http://creativecommons.org/licenses/by/3.0/). 